\title{
APOSENTADORIA ESPECIAL PARA PESSOA COM DEFICIENCIA: APONTAMENTOS E REFLEXÕES INICIAIS
}

André Portella ${ }^{1}$

Antonio Pedro Ferreira da Silva ${ }^{2}$

\section{Resumo}

O objetivo deste trabalho é analisar o benefício criado a partir da Emenda Constitucional no 47/2005, consistente na aposentadoria especial em razão da deficiência do beneficiário, e propor reflexões críticas, tendo como ponto de partida o processo de inclusão das pessoas com deficiência no mercado de trabalho e na cobertura previdenciária. Dentro desta proposta, emerge o problema da dúvida sobre o emprego da expressão lançada no texto constitucional, sobretudo frente a outras terminologias também empregadas socialmente para qualificar a situação fática, como por exemplo, pessoas com necessidades especiais. Por que não foi empregada esta última na redação final do texto da emenda constitucional? Seria ou não mais apropriada? Trata-se de tema recente, tendo em vista a efetiva instituição do benefício em 2013, com a Lei Complementar 142/2013, regulamentada com a Portaria Conjunta 01/2014.

Palavras-chave: Previdência Social. Direito Fundamental. Aposentadoria Especial. Portador De Deficiência

\section{INTRODUÇÃO}

O Sistema de Seguridade Social inaugurado pela Constituição Federal de 1988 sofreu, desde a sua redação original, algumas modificações através de emendas, em razão das pressões legítimas exercidas por setores da sociedade organizada, além da iniciativa do próprio governo no sentido de equalizar as contas públicas.

Entre as modificações promovidas, o Projeto de Emenda à Constituição no 227/2004 deu origem à Emenda Constitucional no $47 / 2005$, e trouxe consigo um novo paradigma em matéria previdenciária, especialmente com a criação da aposentadoria especial em razão da deficiência.

\footnotetext{
${ }^{1}$ Doutor em Direito Financeiro e Tributário pela Universidad Complutense de Madrid, menção honrosa Doctors Europeus; Professor de Direito Finaceiro e Tributário e de Metodologia da Pesquisa Jurídica da UFBA, Professor de Direito Tributário da UNEB e da UCSal, junto aos cursos de Graduação em Direito, Mestrados e Doutorados, e Coordenador da Especialização em Direito Tributário da UCSal; Consultor Jurídico parlamentar para assuntos de Finanças Públicas e Tributação; Coordenador do NEF - Núcleo de Estudos em Tributação e Finanças Públicas; Pesquisador CNPq/FAPESB. E-mail: aaportella@nefportal.com.br.

${ }^{2}$ Procurador federal na Representação da PFE do INSS em Paulo Afonso, Especialista em Direito Tributário, Especialista em Hermenêutica, Mestre em Políticas Sociais e Cidadania pela Universidade Católica de Salvador. E-mail: polsociais@ucsal.br vol.09, n. 01, Rio de Janeiro, 2016.pp. 1-14
} 
A proposta do presente artigo é analisar o novo benefício criado pelo poder constituinte derivado e propor reflexões, tendo como ponto de partida o processo de inclusão das pessoas com deficiência no mercado de trabalho e na cobertura previdenciária.

Em 2010, o censo realizado pelo IBGE (Oliveira, 2012) identificou 20.365.962 pessoas exercendo algum tipo de ocupação e portando pelo menos uma deficiência. Em que pese o fato de que nem todas as pessoas ocupadas são legalmente consideradas seguradas pelo Regime Geral de Previdência Social, é possível verificar que a criação do benefício especial para os deficientes na Constituição e o tratamento legal que the foi conferido alcançará uma parcela significativa de brasileiros.

Ademais, dentro da proposta de estudo será abordada a discussão existente sobre uma provável inadequação do termo 'deficiente', empregado usualmente no Brasil, mas combatido em outros países, dentro da perspectiva da deficiência como determinantes sociais da cidadania, entre outras perspectivas.

\section{ENTRE A VISÃO MÉDICA E A VISÃO SOCIAL DA (D) EFICIÊNCIA: NA BUSCA POR UMA TERMINOLOGIA ADEQUADA}

O ponto norteador do presente artigo é o estudo da aposentadoria especial para a pessoa com deficiência. Dentro desta proposta, emerge uma dúvida sobre o emprego da expressão lançada no texto constitucional, sobretudo frente a outras terminologias também empregadas socialmente para qualificar a situação fática, como por exemplo, pessoas com necessidades especiais. Por que não foi empregada esta última na redação final do texto da emenda constitucional? Seria ou não mais apropriada?

A leitura do relatório final exarado pelo Deputado José Pimentel ${ }^{3}$ durante o processo legislativo do Projeto de Emenda à Constituição no 227/2004, indica que foi apresentada a emenda no 24, proposta pelo Deputado José Carlos Aleluia, onde sugeria a modificação do termo "deficiência" pelo termo "pessoa com necessidades especiais". Em suas considerações, o relator do Projeto rejeitou a emenda, de forma direta, por considerar o termo "deficiência" mais adequado.

Passando para uma análise mais aprofundada sobre a questão, constata-se que a discussão não é nova e há controvérsia sobre a terminologia mais apropriada para tratar, ou melhor, designar, sem estigmatizar, as pessoas que possuem forma corporal e atividade mental distinta das demais. Para Diniz (2007, p. 8), "a concepção de deficiência como uma variação do normal da espécie humana foi uma criação discursiva do século XVIII, e desde então ser deficiente é experimentar um corpo fora da norma”.

\footnotetext{
3 Fonte 
Neste sentido, a percepção do que é normal ou anormal passou a ser tratado como um conceito estético subjetivo com repercussão no campo social, assim, Diniz é clara ao apontar que:

O corpo com deficiência somente se delineia quando contrastado com uma representação de o que seria o corpo sem deficiência. Ao contrário do que se imagina, não há como descrever um corpo com deficiência como anormal. A anormalidade é um julgamento estético e, portanto, um valor moral sobre os estilos de vida. Há quem considere que um corpo cego é algo trágico, mas há também quem considere que essa é uma entre várias possibilidades para a existência humana. (DINIZ, 2012,p.8)

Dentro desta perspectiva, revela-se o porquê da pessoa portadora de uma ou mais deficiências sofrer tantos preconceitos. Enfim, ela passa a conviver com o estigma. Goffman (1988, p.15) ao estudar o estigma esclarece:

Por definição, é claro, acreditamos que alguém com um estigma não seja completamente humano. Com base nisso, fazemos vários tipos de discriminações, através das quais efetivamente, e muitas vezes sem pensar, reduzimos suas chances de vida. Construímos uma teoria do estigma, uma ideologia para explicar a sua inferioridade e dar conta do perigo que ela representa, racionalizando algumas vezes uma animosidade baseada em outras diferenças, tais como as de classe social.

A repercussão no campo social é inevitável, pois nele são traçadas as relações intersubjetivas incluindo todas as formas e possibilidades de corpo. E o estigma possui reflexo social direto e perverso, e é por esta razão que Diniz (2012, p. 9) considera que:

Deficiência é um conceito complexo que reconhece o corpo com lesão, mas que também denuncia a estrutura social que oprime a pessoa deficiente. Assim como outras formas de opressão pelo corpo, como o sexismo ou o racismo, os estudos sobre deficiência descortinaram uma das ideologias mais opressoras de nossa vida social: a que humilha e segrega o corpo deficiente.

O que se vê no campo teórico é o embate entre dois modelos, o médico e o social. A abordagem da deficiência do ponto de vista médico tem como premissa a relação entre a lesão e deficiência. Este foi o modelo que predominou e se enraizou no senso comum. Nesse contexto, considera-se a incapacidade:

Como um problema da pessoa, causado diretamente pela doença, trauma ou outro problema de saúde, requerendo assistência médica, sob a forma de tratamento individual, concedida por profissionais. (Farias e Buchalla apud Cabral et all, 2010, p. 115)

Essa é a visão hegemônica, que orientou as políticas públicas securitárias no Brasil até a Constituição de 1988, e emerge de uma classe profissional que exerce grande influência na sociedade e orienta todo o discurso. Esta premissa é verdadeira, porque a construção do discurso, neste caso, está pautada numa vontade de verdade, que a sociedade moderna e contemporânea buscou através da ciência, e trouxe como resultado a força institucional de determinadas áreas do conhecimento científico a serviço do poder. Nessa linha, Foucaut (2006, p. 20) esclarece:

E a razão disso é, talvez, esta: é que se o discurso verdadeiro não é mais, com efeito, desde os gregos, aquele que responde ao desejo ou aquele que exerce o poder, na vontade de verdade, na vontade de dizer esse discurso verdadeiro, o que está em jogo, senão o desejo e o poder? $\mathrm{O}$ discurso verdadeiro, que a necessidade de sua forma liberta do desejo e libera do poder, não pode reconhecer a vontade de verdade que $\mathrm{o}$ atravessa; e a vontade de verdade, essa que 
se impõe a nós há bastante tempo, é tal que a verdade que ela quer não pode deixar de mascará-la.

Por outro lado, para no modelo social, "[...] a deficiência era resultado do ordenamento político e econômico capitalista, que pressupunha um tipo ideal de sujeito produtivo." (DINIZ, p. 23)

Dentro do modelo social, a $\mathrm{DPI}^{4}$, em 1982, trabalhou com dois conceitos:

1. Deficiência como limitação funcional decorrente de lesão física, sensorial ou mental; e

2. Handicap, como sendo a perda ou a limitação de oportunidade, uma desvantagem (Idem, p. 34)

No Quebec, o tratamento dispensado às crianças "handicaps" tem por perspectiva uma visão não só médica, como também social. Toda a normatização provoca um desafio para toda a sociedade, uma vez que há, para Cabral et all (2010, p. 117), uma mudança na abordagem:

Ao considerar as pessoas "handicaps" como as que apresentam desafios para a integração especial na sociedade, para uma abordagem que inclui esses desafios no conjunto de todos os que dizem respeito à inclusão social para a população em geral. Assim, os problemas de trânsito não são considerados como um problema unicamente das pessoas "handicaps", mas de todas as pessoas e grupos sociais que enfrentam problemas de trânsito nas zonas rurais ou nos bairros carentes das grandes cidades.

Em que pese os argumentos acima declinados, entre 1980 e 1990, a terminologia "handcap" (chapéu na mão) passou a ser fortemente criticada pelos adeptos do modelo social, justamente porque a tradução associava o portador da desvantagem ao pedinte. Dentro desta perspectiva a Organização Mundial de Saúde elaborou a CIF - Classificação Internacional de Funcionalidade, Deficiência e Saúde, onde o termo deficiente teve seu conteúdo modificado, "tendo se transformado em uma categoria guarda-chuva para indicar aspectos negativos de restrições de capacidades, desempenhos e participação" (DINIZ, 2012, p. 54).

A evolução no tratamento da questão evidencia uma preocupação por identificar a melhor forma de abordar a situação vivida pelas pessoas portadoras de pelo menos uma deficiência e a sua inclusão como cidadão, a partir do reconhecimento de que a deficiência é uma determinante social da cidadania. Esta é compreendida neste estudo como "determinantes vinculados aos comportamentos individuais e às condições de vida e trabalho, bem como os relacionados com a macroestrutura econômica, social e cultural." (CNDDS, 2008, p. 3). Além disso, há um cuidado em adequar uma terminologia para o tratamento sem ao mesmo tempo estigmatizar, o que é uma missão de difícil conclusão, principalmente diante das premissas da teoria do estigma, onde Goffman (1988, p. 11) mais uma vez elucida:

A sociedade estabelece os meios de categorizar as pessoas e o total de atributos considerados como comuns e naturais para os membros de cada uma dessas categorias. Os ambientes sociais estabelecem as categorias de pessoas que têm probabilidade de serem neles encontradas.

\footnotetext{
${ }^{4}$ Disable People’s International.
} 
Dentro desta perspectiva, haveria a necessidade de uma modificação na concepção da sociedade em relação ao corpo, tendo como ponto de partida não a adequação do corpo ao espaço, mas a adequação do espaço ao corpo, independente da forma que se apresente. Assim, apesar da OMS adotar a expressão deficiência como a mais adequada a partir da modificação de seu conteúdo, dentro da abordagem social e das determinantes sociais, a terminologia "pessoa com necessidades especiais" parece ser a mais apropriada. Isto porque, passa-se a exigir dos poderes públicos a adequação dos espaços e políticas públicos para todo e qualquer cidadão, independentemente de sua configuração corporal ou mental, abrangendo não só pessoas com de necessidades especiais permanentes, como também aquelas com necessidades especiais transitórias - como por exemplo, a grávida - afinal todos são cidadãos brasileiros.

Em que pese a opção terminológica indicada como mais apropriada, não há como se afastar a utilização do termo "pessoa com deficiência", principalmente pelos entes públicos, uma vez que foi estabelecido pela Convenção sobre Direitos das Pessoas com Deficiência, assinado em Nova York, e confirmado através do Decreto Legislativo no ${ }^{\circ} 186 / 2008$.

Há, no entanto, espaço para discussão e desenvolvimento do conceito, além da busca pela terminologia mais apropriada, isto porque, a própria Convenção, agora incorporada ao direito interno com status de Emenda Constitucional ${ }^{6}$, estabelece o seguinte em seu preâmbulo:

Reconhecendo que a deficiência é um conceito em evolução e que a deficiência resulta da interação entre pessoas com deficiência e as barreiras devidas às atitudes e ao ambiente que impedem a plena e efetiva participação dessas pessoas na sociedade em igualdade de oportunidades com as demais pessoas,

Independente do conteúdo que se dê ao termo deficiência, sempre haverá, do ponto de vista simbólico, uma relação entre a configuração corporal e a sua (d) eficiência produtiva ou para a vida em sociedade. O Estado deve exercer o papel viabilizador e executor de políticas públicas inclusivas, promovendo a adequação de espaços e serviços públicos para todos os cidadãos. Esta é a perspectiva Constitucional inaugurada em 1988, em consonância com a tendência teórica da visão social das pessoas com necessidades especiais, que daria uma amplitude conceitual maior, abrangendo aqueles que têm necessidades especiais permanentes e temporárias, como idosos, gestantes e os portadores de alguma limitação física, sensorial ou mental.

Feitas as considerações em relação às visões médica e social da deficiência, sobretudo no que diz respeito à terminologia mais apropriada, faz-se necessária uma incursão no texto constitucional, para se estudar o sistema de proteção à pessoa com necessidades especiais.

${ }^{6}$ Convenção aprovada nos termos do $\$ 3^{\circ}$ do Art. $5^{\circ}$ da Constituição Federal de 1988. vol.09, n. 01, Rio de Janeiro, 2016.pp. 1-14 


\section{O Sistema CONSTITUCiONAL DE PROTEÇÃo As PESSOAS COM NECESSIDADES ESPECIAIS}

Procedendo a uma pesquisa eletrônica ${ }^{7}$ no texto da Constituição Federal de 1988, tendo como parâmetro a expressão "deficiência”, foram identificadas 15 ocorrências. A primeira indicação está encravada na norma do inciso XXXI do artigo 7º, que estabelece: "proibição de qualquer discriminação no tocante a salário e critérios de admissão do trabalhador portador de deficiência”. A segunda e a terceira ${ }^{8}$ ocorrências recaem sobre os entes federados, indicando a competência comum e concorrente para instituir um sistema de proteção, saúde e assistência públicas em favor dos deficientes.

No próprio texto Constitucional, o constituinte originário estabeleceu normas constitucionais de eficácia contida, que tutelavam as pessoas com necessidades especiais, sobretudo ao estabelecer a reserva de vagas para deficientes, dependendo de lei para sua regulamentação.

Além disso, com a instituição do Sistema de Seguridade Social, a pessoa com necessidades especiais passou a ter um tratamento específico através da Assistência Social ${ }^{9}$, onde se buscou a sua integração social.

$\mathrm{Na}$ linha da proteção, o Constituinte Originário estabeleceu ainda como dever do Estado ${ }^{10}$, a promoção do atendimento educacional especializado às pessoas com necessidades especiais e rede de tutela à criança e ao adolescente com necessidade especial. Finaliza dispondo sobre a necessidade de lei para regulamentar a adaptação de espaços públicos e de bens de consumo para os portadores de necessidade especial.

É importante salientar que a Convenção, ratificada pelo Decreto Legislativo nº 186/2008, encontrou um sistema de proteção para as pessoas com necessidades especiais bastante avançado. A sua contribuição para o texto constitucional está relacionada diretamente aos princípios específicos sobre o tema, os quais se constituem, é verdade, em desdobramentos de princípios constitucionais constantes no artigo $5^{\circ}$ da Constituição Cidadã, como por exemplo, o princípio da igualdade e da isonomia. Além de se fundar no princípio da dignidade da pessoa humana, orientador de todo o Sistema Constitucional Brasileiro.

Dentro desse contexto, a aprovação da Emenda 47/2005 revelou, durante todo o processo legislativo, a importância do tema e o seu reflexo na seara previdenciária, isto porque, diante das políticas públicas inclusivas das pessoas com necessidades especiais permanentes no mercado de trabalho, o reflexo no campo previdenciário seria um efeito natural. Nesse passo, a necessidade de tratamento isonômico para o segurado com necessidade especial permanente se tornou essencial.

\footnotetext{
${ }^{7}$ Foi utilizada a ferramenta de pesquisa do "Google Chrome", com a função ctrl+f.

${ }^{8}$ Artigo 23, inciso II e artigo 24, inciso XIV da CF/ 1988.

${ }_{9}^{9}$ Artigo 203, incisos IV e V da CF/ 1988.

${ }^{10}$ Artigo 207, inciso III da CF/ 1988.
} 


\section{O PARADIGMA PREVIDENCIÁRIO INAUGURADO PELA EMENDA CONSTITUCIONAL No $47 / 2005$}

Procedendo à análise do histórico normativo do Sistema Previdenciário Brasileiro, é possível notar que a Lei Eloy Chaves ${ }^{11}$, primeiro instrumento legal previdenciário pátrio, criou as caixas de aposentadorias e pensões, mas não tinha em seu conteúdo qualquer relação entre o tempo de contribuição e o tipo de trabalho exercido pelo segurado.

Nesse passo, o próprio surgimento das leis trabalhistas e a sua posterior consolidação, criou um campo propício para uma preocupação com o tipo de atividade exercida pelo trabalhador, reconhecendo-se que algumas tinham reflexos diretos na saúde. Assim, a Lei 3.807/1960 instituiu a aposentadoria especial, com requisitos mistos de tempo de contribuição, carência e idade, estes, respectivamente, modificado e suprimido como requisito (DEUD, 2005, p. 03).

O Decreto no 48.959-A/1960 regulamentou a concessão da aposentadoria especial e estabeleceu quais eram as atividades penosas, insalubres e perigosas. E continha uma previsão de revisão do quadro que estabelecia estas atividades especiais. Fato que ocorreu com a publicação do Decreto 53.831/1964 ${ }^{12}$, que também passou a exigir a exposição habitual e permanente aos agentes nocivos, conforme se depreende do artigo $3^{\circ}$ deste diploma normativo. O Decreto 83.080/1979 passou a considerar algumas atividades profissionais como sendo especiais, não só em razão da exposição aos agentes nocivos, mas também por enquadramento em grupo profissional, fazendo jus à redução do tempo de serviço.

A Lei 9.032/1995 promoveu grandes modificações nessa matéria, pois reforçou a exigência da exposição aos agentes nocivos de forma habitual e permanente, além de retirar o enquadramento profissional. Já o Decreto 2.172/1997 $7^{13}$, que regulamentou a Lei 9.528/1997, passou a relacionar quais os agentes considerados nocivos para efeito de enquadramento especial.

Toda a estrutura legal construída historicamente evidencia que a aposentadoria especial sempre teve como pressuposto o exercício de atividade laboral que impacta na saúde do trabalhador, sendo normatizado o tratamento isonômico com os demais trabalhadores que não se submetem a condições especiais de trabalho. Em outras palavras, o foco para a concessão do aposento especial era o exercício da atividade laboral que gerava prejuízo à saúde do trabalhador.

\footnotetext{
${ }^{11}$ Decreto no $4.682 / 1923$.

12 "Art $3^{\circ} \mathrm{A}$ concessão do benefício de que trata êste decreto dependerá de comprovação pelo segurado efetuado na forma prescrita pelo art. 60, do Regulamento Geral da Previdência Social, perante o Instituto de Aposentadoria e Pensões a que estiver filiado do tempo de trabalho permanente e habitualmente prestado no serviço ou serviços, considerados insalubres, perigosos ou penosos, durante o prazo mínimo fixado."

${ }^{13}$ A recente jurisprudência do STJ tem decidido no sentido de que é possível o enquadramento de período como especial, mesmo quando o agente nocivo não constar no Decreto 2.172/1997.
} 
Frise-se que até 1995, apenas o segurado empregado e o avulso poderiam ser beneficiários da aposentadoria especial. No entanto, a Lei $10.666 / 2003$ passou a incluir os contribuintes individuais que trabalhavam em cooperativas, desde que o trabalho fosse considerado nocivo à saúde (ALENCAR, 2007, p. 438).

Dentro desse contexto, se, em essência, a aposentadoria especial está relacionada ao trabalho submetido a condições especiais, principalmente, em razão da exposição aos agentes nocivos legalmente previstos, com a instituição da aposentadoria especial para pessoas com deficiência ${ }^{14}$, modifica-se a perspectiva, pois, é a condição pessoal do trabalhador e a sua relação com o trabalho, numa visão funcional, que influenciará o direito ou não ao benefício. Este é o novo paradigma criado pela Emenda Constitucional 47/2005 $5^{15}$, ao estabelecer a ressalva: "[..] os casos de atividades exercidas sob condições especiais que prejudiquem a saúde ou a integridade física e quando se tratar de segurados portadores de deficiência ${ }^{16}$, nos termos definidos em lei complementar".

A Lei Complementar 142/2013 estabelece em seu artigo $2^{\circ}$ o conceito de pessoa com deficiência, seguindo a linha indicada pela Convenção mencionada alhures:

Pessoa com deficiência aquela que tem impedimentos de longo prazo de natureza física, mental, intelectual ou sensorial, os quais, em interação com diversas barreiras, podem obstruir sua participação plena e efetiva na sociedade em igualdade de condições com as demais pessoas.

A instituição e regulamentação da aposentadoria especial para a pessoa com deficiência é reflexo da luta pela efetividade da cidadania social, empreendida pelas pessoas com necessidades especiais. Estas pessoas superam barreiras não só físicas, como também sociais, situação fática que exigia um tratamento isonômico com os demais trabalhadores. Afinal, o Estado é objeto e criação do sujeito ${ }^{17}$ (homem), e todo homem é cidadão, independentemente de sua configuração corporal, neste sentido cabe a lição de Liberati (2013, p. 82) que esclarece:

A atuação estatal aponta sua atividade para a satisfação das necessidades e direitos das pessoas, que têm assegurada, no texto constitucional, a proteção da dignidade, da liberdade, da intimidade e de outros tantos direitos subjetivos individuais e coletivos.

A aposentadoria especial para pessoas com deficiência é um direito social conquistado e se constitui na efetividade das normas que garantem a cidadania social, nesse ponto, a lição de Luís Roberto Barroso (2009, p. 82) é importante, ao indicar o conceito de efetividade como sendo:

A realização do Direito, o desempenho concreto de sua função social. Ela representa a materialização, no mundo dos fatos, dos preceitos legais e simboliza a aproximação, tão íntima quanto possível, entre o dever-ser normativo e o ser da realidade social.

Feitas essas considerações, diante de um sistema de proteção às pessoas com deficiência e da instituição da aposentadoria especial para estas pessoas é importante se refletir sobre algumas questões.

\footnotetext{
${ }^{14}$ Em que pese, considerar o termo pessoa com necessidades especiais como sendo o mais apropriado, a partir deste subtítulo será empregada a denominação contida tanto na Emenda 45/2005, quanto nos dispositivos legais.

${ }^{15} \mathrm{~S} 1^{\circ}$ do art. 201 da Constituição Federal do Brasil de 1988.

${ }^{16}$ Dentro da lógica capitalista, o homem é arrebatado de sua condição de sujeito e se transforma em objeto (Marx, 1989).

${ }^{17}$ Dentro da lógica capitalista, o homem é arrebatado de sua condição de sujeito e se transforma em objeto (Marx, 1989). vol.09, no. 01, Rio de Janeiro, 2016.pp. 1-14 


\section{REFLEXÕES SOBRE A APOSENTADORIA ESPECIAL PARA PESSOA COM DEFICIÊNCIA}

O beneficio foi conquistado, mas para a sua fruição depende do preenchimento dos requisitos exigidos pela lei. Nesse ponto, o primeiro a ser cumprido é comprovar a qualidade de segurado pelo Regime Geral de Seguridade Social-RGPS. Este requisito é importante, uma vez que ele garante o acesso ao Sistema Previdenciário, que não se confunde com os outros ramos do Sistema de Seguridade Social (SILVA, 2014). E a Lei 8.213/1991 estabelece claramente quem são os segurados pelo RGPS.

Desde já, uma questão diferenciadora emerge em razão do novo paradigma já abordado, porquanto, se há uma restrição às espécies de segurado - empregado, avulso, contribuinte individual cooperativado relacionando-o com o exercício da atividade, para se viabilizar o aposento especial, no caso da aposentadoria especial para a pessoa com deficiência (termo legal), não há esta distinção, ou seja, qualquer trabalhador com deficiência, independentemente de sua categoria de segurado ${ }^{18}$, pode pleitear o benefício, conforme consta no artigo $1^{\circ}$ da Lei complementar 142/2013, a única exceção é o segurado especial, que já goza de duplo benefício (redução da idade e desnecessidade de contribuição).

Outro ponto de tensão está relacionado com a aferição da deficiência e seu grau, isto porque, como já visto, a avaliação não será estritamente médica, mas também funcional. A nova configuração da avaliação médica certamente trará repercussão na seara dos benefícios por incapacidade. Isto porque, partindo de uma visão médico-social, nem toda doença será incapacitante, de tal sorte que, haverá a necessidade de avaliação do grau de limitação laboral, para a concessão dos benefícios por incapacidade, justamente para não prejudicar o segurado.

Nesse passo, a avaliação da possibilidade de exercício de atividades compatíveis com a doença, ao invés de remeter o segurado para a inatividade ${ }^{19}$, haverá um novo ponto de partida, pois, mantendo-se em exercício e ocorrendo o enquadramento, ainda que haja uma melhora, poderá beneficiar-se com as regras da lei complementar.

Não se deve olvidar que, só pode ser considerado deficiente para efeito de aposentadoria especial, o segurado com deficiência que trabalha. Esta é a ideia que se abstrai da norma constante no artigo $6^{\circ}, \mathbb{} 1^{\circ}$ e artigo 70, ambos da LC 142/2013, podendo a deficiência ser anterior à vigência da lei. Então qual é o ponto de distinção entre a incapacidade e a deficiência, para efeitos previdenciários?

A interpretação sistemática da legislação indica que a pessoa que apresenta um impedimento para o exercício de atividades laborais, em razão de doença ou enfermidade, preenchendo os demais requisitos poderá

\footnotetext{
${ }^{18} \mathrm{O}$ artigo 70 -B do Decreto 8.145/2013 estabelece as categorias de segurado que podem fruir o benefício.

${ }^{19}$ Os benefícios por incapacidade (auxílio-doença e aposentadoria por invalidez) são incompatíveis com o exercício de atividades laborais, sendo cessados com a verificação do retorno ao trabalho.
} 
fruir o auxílio-doença e a aposentadoria por invalidez. Por outro lado, o segurado que apresenta uma deficiência, que não o impede do exercício de uma atividade laboral compatível poderá ser favorecido pela regra.

Dentro desta perspectiva, uma pessoa em gozo de aposentadoria por invalidez ou auxílio-doença, mesmo apresentando uma deficiência não fará jus ao benefício, uma vez que há a necessidade de se comprovar o exercício da atividade laboral estando com a deficiência, salvo se o segurado já tenha ingressado no RGPS com a deficiência, e durante o período tenha ocorrido o impedimento laboral. Por esta razão, tanto a lei, quanto o decreto indica a necessidade de se fixar a data de início da deficiência, especificando o grau em cada período notado.

Da mesma forma, ao fixar a data de início da deficiência e o seu grau em cada período será importante para delimitar a aplicação dos fatores de conversão e o aproveitamento do período laborado sem a deficiência.

Destaque-se ainda que a aferição da deficiência será realizada por perícia encampada pela autarquia previdenciárias (INSS - Instituto Nacional do Seguro Social), através de seu corpo de peritos, que além dos exames médicos e análise dos relatórios e exames complementares, submeterão os segurados aos questionários criados com base na Classificação Internacional de Funcionalidade, Incapacidade e Saúde - CIF, da Organização Mundial de Saúde, seguindo a orientação da Convenção sobre os Direitos das Pessoas com Deficiência, como já apontado, incorporado ao direito pátrio com status de Emenda Constitucional. Este questionário se apresenta na forma de ranking de respostas (MINAYO, 2005, p. 112), para indicar, por fim, o grau de deficiência do segurado.

Feitas estas considerações, emerge um questionamento, todos os segurados beneficiários de auxílioacidente fariam jus à aposentadoria especial para o segurado com deficiência? A resposta está relacionada diretamente com a perícia, pois, nem sempre o beneficiário auxílio-acidente será considerado deficiente, a análise é caso a caso.

Outro ponto para reflexão é a vedação da cumulação do enquadramento em razão da deficiência, com o enquadramento em razão da exposição aos agentes nocivos. Ambas as regras favorecem ao segurado com a redução do tempo de contribuição, desta forma, caso fosse permitida a cumulação, haveria um duplo favorecimento para os segurados deficientes, situação que violaria diretamente o princípio da isonomia. Por outro lado, apesar de vedada a cumulação, é possível a opção pelo benefício mais favorável, conforme orienta o $\operatorname{decreto}^{20}$.

Por fim, o último ponto de reflexão está vinculado à fonte de custeio para o novo benefício instituído. Este dado é essencial, uma vez que a própria Constituição Federal, no art. 195, $₫ 5^{\circ}$, estatui que "nenhum benefício ou serviço da seguridade social poderá ser criado, majorado ou estendido sem a correspondente fonte de custeio

\footnotetext{
${ }^{20}$ Artigo 70-G do Decreto 8.145/2013.
} 
total". Frise-se que as atividades laborais submetidas aos agentes nocivos possuem todo um sistema de custeio, a partir da tributação especial das empresas, gestor de mão de obra ou cooperativas.

Em relação à aposentadoria especial para pessoa com deficiência, ocorreu um fato "sui generis" durante o processo legislativo. A leitura do parecer aprovado pela Comissão de Finanças e Tributação da Câmara Federal evidencia uma falha durante o processo e elaboração da lei, que não foi sanado. O relator Dep. Marcos Pestana ${ }^{21}$ em seu relatório foi claro ao indicar que durante o processo legislativo na Câmara, o projeto de lei no 227/2005 não foi apreciado pela Comissão de Finanças e Tributação, mas ainda assim, foi encaminhado para o Senado, restringindo-se o seu relatório, naquele momento, à apreciação do impacto das modificações ocorridas no Senado, que inexistiram. Prescindindo da análise global do projeto em relação à fonte de custeio.

Em outras palavras, a aposentadoria especial para a pessoa com deficiência foi criada, com regras de redução de idade e tempo de contribuição, as quais impactam no Regime Geral de Previdência na forma de despesa, mas não foram indicadas as fontes de custeio. A situação aponta um erro no procedimento formal legislativo, situação que implica numa provável arguição de inconstitucionalidade perante o STF. Mas, enquanto esta não ocorrer, as despesas geradas pela concessão do modelo de aposentadoria estudado serão custeadas pelo próprio RGPS, com base no princípio geral da solidariedade.

\section{CONSIDERAÇÕES FINAIS}

A aposentadoria especial para a pessoa com deficiência se constitui numa conquista histórica para uma parcela significativa da população brasileira, que supera as limitações impostas por uma configuração corporal ou mental diferente, e também pela própria sociedade, mas consegue ingressar no mercado de trabalho.

É importante destacar que a Constituição Cidadã já contava com um microssistema de proteção às pessoas com deficiência, que garantia a isonomia e o acesso ao trabalho. Mas o debate em relação a esta proteção, não é restrito ao Brasil, mas também em outros países, de tal sorte que gerou a Convenção sobre Direitos das Pessoas com Deficiência, assinado em Nova York, e confirmado através do Decreto Legislativo no 186/2008, sendo incorporado ao direito pátrio com o status de Emenda Constitucional.

Entre as discussões existentes na atualidade, a que se desenvolve em relação ao termo mais apropriado para designar as pessoas com uma configuração corporal ou mental diferenciada ganha importância, de tal sorte que a mencionada Convenção é clara ao indicar que o conceito de deficiência está em evolução. Se o conceito inicialmente esteve relacionado com a visão médica da deficiência, outras terminologias, como "handicaps" trouxe a relevância para a visão social, apesar das críticas apontadas contra a terminologia.

\begin{tabular}{l}
\hline Fonte \\
http://www.camara.gov.br/proposicoesWeb/prop_mostrarintegra? codteor=1064174\&filename=Tramitacao- \\
PRL+1+CFT+\%3D\%3E+PLP+277/2005. Acesso em: 04 set. 2014 .
\end{tabular} 
A Convenção afasta a visão médica exclusiva e passa a ampliar o conceito de deficiência, com a visão médica e social, indicando que não é a pessoa que deve se adequar ao espaço público e à sociedade, mas esta deve estar preparada para acolher os cidadãos independentemente da sua configuração corporal ou mental.

Dentro desta perspectiva, houve a opção pela expressão "pessoa com necessidades especiais", que podem ser permanentes ou temporárias. O espaço e serviço públicos devem ser adaptados, a escola deve ser adaptada, a sociedade em geral deve estar preparada para receber o cadeirante, a gestante, o idoso, o autista, etc. Este é o grande desafio para a inclusão sem estigmatizar.

Por outro lado, não se pode olvidar o fato de que a Convenção é clara ao indicar a expressão "pessoa com deficiência" como a mais apropriada e Constitucionalmente posta, não podendo o Estado fugir desta indicação.

Entre os apontamentos e reflexões propostos especificamente em relação à aposentadoria especial para pessoa com deficiência, constata-se que há situações onde o judiciário certamente será provocado, seja para avaliar a constitucionalidade da Lei Complementar no 142/2013, seja para corrigir ou ratificar a modulação do grau de deficiência, ou, por fim, para consolidar a interpretação dos dispositivos normativos, com o intuito de alcançar fatos integrantes da zona cinzenta entre a lei e o mundo real.

Enfim, o instituto apesar de a previsão constitucional ser datada de 2005, apenas em 2013 foi instituído com a lei complementar e finalmente regulamentado com a Portaria Conjunta no 1/2014. Em outras palavras, não há um posicionamento por parte da jurisprudência dos Tribunais Superiores, só restando aos operadores do direito desbravar esta nova fronteira da seara previdenciária.

\title{
RETIREMENT FOR PERSON WITH DISABILITIES: NOTES AND REFLECTIONS
}

\begin{abstract}
The objective of this study is to analyze the benefit created from the Constitutional Amendment 47/2005, consisting of special retirement on grounds of disability of the beneficiary, and propose critical reflections, taking as its starting point the process of inclusion of disabled people in the market work and social security coverage. Within this proposal, emerges the problem of doubt about the use of the expression launched in the Constitution, especially compared to other terminologies also socially employed to describe the factual situation, such as people with special needs. Why was it not used the latter in the final wording of the text of the constitutional amendment? It would be more appropriate or not? It is recent theme, with a view to effective institution of the benefit in 2013, with the Complementary Law 142/2013, regulated by Ordinance 01/2014.

Keywords: SOCIAL SECURITY. FUNDAMENTAL RIGHT. SPECIAL RETIREMENT. CARRIER OF DISABILITIES
\end{abstract}




\section{REFERENCIAS}

ALENCAR, Hermes Arrais. Benefícios previdenciários. 3a Edição. São Paulo: LEUD, 2007.

BARROSO, Luís Roberto. O direito constitucional e a efetividade de suas normas - limites e possibilidades da Constituição brasileira. 9a Edição. Rio de Janeiro: Renovar, 2009.

BAUMAN, Zigmunt. Capitalismo parasitário e outros temas contemporâneos. Tradução de Eliana Aguiar. Rio de Janeiro: Zahar, 2010

BRASIL. Constituição da República Federativa do Brasil de 1988. Disponível em: http://www.planalto.gov.br/ccivil_03/constituicao/constituicaocompilado.htm. Acesso em 29 ago. 2014.

Lei complementar 142/2013. Regulamenta o $\mathbb{1} 1^{\circ}$ do art. 201 da Constituição Federal, no tocante à aposentadoria da pessoa com deficiência segurada do Regime Geral de Previdência Social - RGPS. Disponível em: < http://www.planalto.gov.br/ccivil_03/leis/lcp/Lcp142.htm>. Acesso em 31 ago.2014.

Decreto legislativo $n^{\circ}$ 186, 09 de julho de 2008. Aprova o texto da Convenção sobre os Direitos das Pessoas com Deficiência e de seu Protocolo Facultativo, assinados em Nova Iorque, em 30 de março de 2007. Disponível em: < http://www.planalto.gov.br/ccivil_03/constituicao/congresso/DLG/DLG-186-2008.htm>. Acesso em 29 ago. 2014.

CABRAL, Ivone Evangelista; LEAL, José Roberto; PERREAULT, Michel. Experiência Brasil-Canadá no cuidado social e na saúde da criança com necessidades especiais: aproximações e distanciamentos. Interfaces Brasil/Canadá, Rio Grande do Sul: 2010. Disponível em: <http://www.revistas.unilasalle.edu.br/index.php/interfaces/article/view/572/441 >. Acesso em 16 ago. 2014.

COMISSÃO NACIONAL SOBRE OS DETERMINANTES SOCIAIS DA SAÚDE (CNDSS). As causas sociais das iniqüidades em saúde no Brasil. Rio de Janeiro, abr. 2008. Disponível em $<w w w$. determinantes.fiocruz.br>. Acesso em: 24 mai. 2014.

DEUD, Claudia Augusta Ferreira. Legislação relativa à aposentadoria especial. Brasília: Biblioteca Digital da Câmara dos Deputados, 2005.2 Disponível em: $<$ bd.camara.gov.br/bd/bitstream/.../legislacao_aposentadoria_deud.pdf $>$. Acesso em: 31 ago. 2014.

DINIZ, Débora. O que é deficiência. São Paulo: Brasiliense, 2007.

FOUCAULT, Michel. A ordem do discurso. Tradução de Laura Fraga de Almeida Sampaio. 13a edição. São Paulo: Edições Loyola, 2006.

GOFFMAN, Erving. Estigma: Notas sobre a Manipulação da Identidade Deteriorada. Tradução de Marcia Bandeira de Mello Leite Nunes. 4a edição. Rio de Janeiro: LTC, 1988.

LIBERATI, Wilson Donizeti. Políticas públicas no Estado Constitucional. São Paulo: Atlas, 2013.

MARSHALL, T. H. Cidadania e classe social. In: Cidadania, classe social e status. Rio de Janeiro: Zahar, 1967. p. 57- 114. 
MARX, K. K. Marx: Trabalho alienado e superação positiva da auto-alienação humana (Manuscritos econômicofilosóficos de 1844). In: FERNANDES, Florestan (org.). K Marx e F. Engels, História. 3a Edição. São Paulo: Editora Ática, 1989. p. 146-164.

MINAYO, Maria Cecília de Souza et al (Org.). Avaliação por triangulação de métodos: abordagem de programas sociais. Rio de Janeiro: Editora Fiocruz, 2005.

OLIVEIRA, Luiza Maria. Cartilha do Censo 2010 - Pessoas com Deficiência. Brasília: SDH-PR/SNPD, 2012.

SILVA, Antonio Pedro Ferreira da. Sistema de seguridade social brasileiro - panorama geral e reflexões. Jus Navigandi, Teresina, ano 19, n. 3938, 13 abr. 2014. Disponível em: <http://jus.com.br/artigos/27644>. Acesso em: 1 set. 2014.

Trabalho enviado em 02 de junho de 2015.

Aceito em 07 de agosto de 2015. 